\title{
Culture, Gender, and School Leadership: School Leaders' Self-perceptions in China
}

\author{
Wing-Wah Law \\ The University of Hong Kong
}

\begin{abstract}
Numerous studies have demonstrated the influences of culture and gender on leadership, including school leadership. Such studies have been criticised, however, for being dominated by Anglo-American paradigms and frameworks and for under-exploring the roles of culture and gender on leadership in non-Western societies. With reference to China, this paper focuses on the relationship between gender and school leadership and explores gender differences between Chinese male and female school leaders in their leadership orientations. The study adopted a mixed methodology of a questionnaire survey and individual interviews to solicit Chinese school leaders' views in 2008. The study finds mixed patterns of gender differences in Chinese school leadership, including stereotypical, non-stereotypical, and no differences. This paper argues that these patterns can be interpreted as resulting from the dynamic interplay among traditional Chinese culture, contemporary political context, and organisational settings into which Chinese school leaders are socialised and in which their leadership styles and behaviours are shaped and leadership is exercised.
\end{abstract}

\section{Introduction}

The literatures on culture and leadership and on gender and leadership have demonstrated that cultures have different values, norms, traditions, and practices, which in turn can differently shape perceptions of gender roles in society in general, and on leadership in particular. Both types of literature have been criticised, however, for being dominated by paradigms and frameworks from Anglo-American societies and for under-exploring the influences of culture and gender on leadership in other societies (Dimmock and Walker 2000; Oplatka 2006). Although the literature of culture and leadership has been supplemented by some studies on non-Anglo-American societies (e.g., Fidler 2000; Hofstede 1980), there has been a lack of research addressing the complicated relationship between gender and leadership in non-Western societies, as Oplatka (2006) pointed out; this warrants attention.

As part of a project on culture and leadership, this study explores gender differences between Chinese male and female school leaders in major orientations of leadership preferences and practices. These orientations, as shown later, are dichotomized in Chinese leadership studies into Chinese and Anglo-American leadership traditions in the comparative literature of leadership. Interestingly, many elements of these orientations overlap with those used to describe stereotypical gender polarities between male and female leaderships in Anglo-American and Chinese gender studies. In 2008, this project conducted a questionnaire survey with about 350 Chinese school leaders (including school principals, school party secretaries, and their deputies) and individual interviews with 20 Chinese school leaders in several areas of China. The study reveals the coexistence of mixed gender patterns in Chinese school leadership: stereotypical, non-stereotypical, and no differences. Such coexistence can be interpreted as resulting from a dynamic interplay among traditional Chinese culture, contemporary political context, and organisational settings into which school leaders are 
socialised and in which their leadership styles and behaviours are shaped and leadership is exercised.

The article first reviews comparative literature of culture and leadership and studies of gender and school leadership. Next, it outlines the study's design and procedures. Third, it presents survey findings on the patterns of gender differences between Chinese male and female leaders' adoption of leadership orientations. Fourth, it offers some possible explanations from both cultural and social perspectives for these patterns by grounding them mainly on interview findings. Finally, it concludes by highlighting theoretical implications for understanding culture, gender, and school leadership.

\section{Culture, gender, and school leadership}

\section{Cultural dichotomies between Anglo-American and Chinese leadership traditions}

The field of comparative leadership features two contrasting views about the relationships between culture and leadership. Advocates of the universal view of leadership (e.g., Dorfman et al. 2004) contend that some traits of outstanding leaders adopting transformational leadership, such as effective communication and trustworthiness, are universally endorsed across cultures, whereas proponents of the cultural-specific perspective (such as Hofstede $1984 ; 2007)$ argue that leadership styles and practices vary across cultures.

As an extension of the latter view, many Chinese leadership studies (e.g., Ceng 2005; Hong and Engeström 2004; Su 2005) have considered Chinese and Anglo-American cultures as two different paradigms for explaining and understanding leadership styles and practices. Hofstede (1980; 1984) and Qi, Wu, and He (2007) broadly take the view that a collectivistic orientation is emphasised more in Chinese leadership traditions than in Anglo-American ones. Chinese organisations, as Hofstede $(1980 ; 1984)$ argued, are further characterized by a large 'power distance' between leaders and subordinates.

More specifically, Lowe (2003) proposed four contestable dichotomies between Chinese and Anglo-American leadership traditions: (1) between a collectivist-cooperative orientation (focusing on interpersonal relationships and group interests) and an individualistic-competitive orientation (stressing efficiency, competition, and personal reward); (2) between an autocratic/paternalist orientation (emphasising obedience, observing rules, and respect for seniors) and a democratic orientation (stressing participation and team spirit); (3) between an intuitive orientation (emphasising the use of inductive reasoning to find best practices and the cultivation of unfolding change) and a rational orientation (with stress on rationality and objectivity) in decision-making; and (4) between a long-term orientation (in preparing succession) and a short-term orientation (stressing strategies of entry and exit) (see Tables 1 and 3).

\section{[Table 1 about here]}

These four cultural dichotomies between Chinese and Anglo-American leadership traditions, as the author argues elsewhere (citation not revealed at the review stage), are contested, however, especially in an increasingly globalized world. Despite this, the first three cultural dichotomies between these two traditions in the literature of comparative leadership, as shown in the next section, share striking similarities with Anglo-American and Chinese studies in the use of terms and characteristics describing stereotypical differences in leadership traits and styles between male and female leaders. 


\section{Gender and leadership in Anglo-American studies}

Similar to the comparative literature on culture and leadership, Anglo-American studies have debated whether leadership is gender-neutral or gender-specific. There are three broad views on relationships between gender and leadership: the 'stereotypical differences' approach, the 'non-stereotypical differences' approach, and the 'no differences' approach (Powell 1997). Despite different emphases and extents, these three approaches start with a basic gender stereotype: a masculine-feminine paradigm. As summarized in some Anglo-American studies (e.g., Coleman 2003; Gray 1987; Krüger 2008), men are perceived as being independent, objective, rational and analytical, formal, competitive and aggressive, conformist and normative, dominant and strong, and sure of themselves, while women are supposed to be much more dependent, subjective, emotional, informal, cooperative and collaborative, intuitive and creative, sensitive and weak, and not sure of themselves but caring and nurturing. Some of these perceived male traits (e.g., being objective, rational and analytical) are similar to those used in the rational domain of Chinese leadership studies to describe AngloAmerican leadership, while some female traits (e.g., being cooperative) are similar to those used to describe the intuitive domain of Chinese leadership.

Based on this masculine-feminine paradigm, advocates of the 'stereotypical differences' approach in Anglo-American studies have argued that male and female leaders in business and education have different qualities and leadership traits and therefore different leadership styles. Generated from this approach are three related, stereotypical gender dichotomies. First, some studies argue that leadership roles are often seen 'masculineoriented' and marked by 'behaviors of authority and discipline', and therefore do not match such feminine traits as being emotional and nurturing (Sanchez and Thornton 2010, p. 4). This masculine leadership style described in Anglo-American studies is somewhat similar to the autocratic/paternalist orientation in the Chinese leadership tradition, which emphasises rule, authority, and obedience (see Table 1).

The second stereotypical gender dichotomy identified in Anglo-American studies is related to the selection of leadership styles. Male leaders tend to employ a task orientation, whereas female leaders are inclined to adopt an interpersonal orientation (Pace and Pace 2005). According to Eagly, Makhijani, and Klonsky (1992b, p. 6), task-oriented styles include leadership behaviours that demand high-level performance, require subordinates to follow rules and procedures, and make a clear distinction in status between leader and subordinates, whereas interpersonal styles comprise those behaviours helping subordinates, 'looking out for their welfare, explaining procedures, being friendly and available'. The last two characteristics of the task orientation are similar to observing seniors' rules and a large 'power distance' between leaders and the led in the autocratic/paternalist orientation of Chinese leadership, whereas the first two features of the interpersonal orientation are similar to the emphasis on group interests in the collective-cooperative one of Chinese leadership.

The third gender dichotomy in Anglo-American gender studies shares the same terms and similar features with the third cultural dichotomy between the 'autocratic' orientation of Chinese leadership and 'democratic' one of Anglo-American tradition in the comparative leadership literature. As Eagly and Johnson (1990, p. 247) argued, male leaders tend to choose a more 'autocratic' orientation, whereas female leaders are inclined to employ a more 'democratic' orientation. In particular, some gender studies (e.g., Eagly and Johnson 1990; Eagly et al. 1992a; Ferrario 1994) have contended that male leaders tend to adopt a more topdown, command-control, directive leadership style, whereas female leaders prefer a more democratic, participative, collaborative, interactive, and group-oriented leadership style. In a similar vein, Sanders, Willemsen, and Millar (2009, p. 302) argued that male leaders tend to 
prefer 'power oriented cultures,' while female leaders prefer 'people oriented cultures'. As compared with their male counterparts, women leaders stress more cohesiveness, value more group activities, have less distance from subordinates, and have more informal and flexible agendas (Ozga 1993).

Unlike the 'stereotypical differences' approach, a narrow version of the 'nonstereotypical differences' approach explains how early socialisation experiences could put female leaders and managers in a disadvantaged position in their leadership careers. In the workplace, including schools, which are still structured with the societal patterns of the past male-dominant society (MacLeod 1994), women's advancement to the highest level of management is often inhibited by a 'glass ceiling' comprising both internal and external barriers arising from personal sex-role orientations, earlier socialisation and stereotyping, organisational constraints, and societal power relations (Cubillo and Brown 2003; Lynn Davies 1987). To break this glass ceiling, female leaders and managers, as contended by the 'non-stereotypical' approach, need to be exceptional by compensating for early socialisation experiences to meet masculinity-related organisational expectations (Powell 1997). This perspective does not apply to men in leadership positions, however.

A more inclusive version of the 'non-stereotypical differences' approach is the theory of androgyny or cross-gender homogeneity, which includes male leaders' employment of feminine leadership styles. It holds that male and female school leaders can amalgamate their own leadership characteristics and styles with those of the opposite gender. In a study on American educational leaders, Thompson (2000) explained that as more women take up school leadership, female leaders have greater confidence in employing more diverse leadership styles and amalgamating traditionally feminine leadership features with masculine ones. Similarly, Coleman (2003, p. 32) found that male and female school principals in England aspired to a cross-gender and amalgamated 'leadership that is collaborative, caring and people-oriented', most likely because they were influenced by popular leadership paradigms, including transformational and participative leadership.

Unlike the 'stereotypical differences' and 'non-stereotypical' approaches, the 'no differences' approach argues that despite some variations, male and female leaders do not conspicuously differ in task-oriented style, interpersonal-oriented style, and leadership effectiveness (Donnell and Hall 1990; Powell 1997). Powell and Graves (2003, p. 151) even contended that female leaders are 'no more or less effective' than their male counterparts, and that whether male or female leaders are effective is not influenced by gender, but by situational factors, such as the nature of the organisational setting and the leader role, the managerial level of the position, and the proportion of male leaders and followers.

Despite these diverse views, Oplatka (2006, p. 607) criticised the literature on gender and leadership for being dominated by research 'drawn almost exclusively on perspectives and realities taken from Anglo-American literature and practice', having little knowledge about developing countries that differ from developed countries in cultures and social contexts, and therefore lacking a complete perspective on gender and leadership in the world.

\section{Gender stereotypes and leadership in Chinese leadership studies}

As compared to their Anglo-American counterparts, relationships between gender and school leadership in developing countries such as China are under-researched, and this warrants attention. Anglo-American and Chinese cultures share similar gender stereotypes. As in Anglo-American societies, leadership, including school leadership, in China has been maledominated. Traditional Chinese culture, as represented by Confucianism, emphasised the importance of submission and obedience in feudal hierarchical society. With a view to maintaining social stability and harmony, Confucianism promoted three cardinal guides in 
human relationships: emperor guiding officials, father guiding son, and husband guiding wife. Related to the last pair were two basic gender-stereotypical notions, which, as many studies have pointed out (e.g., Fang Chen 1998; Ping Liu 1997), had been perpetuated in traditional Chinese culture for more than two millennia. The first notion was related to the cultural mentality of males' superiority over females (nanzun nubei) and putting more emphasis on males than females (zhongnan qingnu). In families, women were expected to be submissive and obedient to different men at three stages of life (san cong): father before marriage, husband during marriage, and son after husband's death. Women were also encouraged to have four virtues (si de): upholding fidelity (de), being mindful in speech (yan), keeping decent physical appearance (rong), and being good at taking care of family matters (gong). The second notion was an explicit cultural expression of stereotypical gender roles: women at home and men outside the home (nan zhu wai nu zhu nei). Women had far fewer opportunities for education and upward social mobility than men. There was even a Chinese saying against education for women: 'It is a virtue for women to have no talent' (nuzi wucai bian shi de).

In the $20^{\text {th }}$ century, these two gender stereotypes in China were challenged by three major movements. The first one was women intellectuals' demand for freedom in marriage and gender equality in the May Fourth Movement in the Republic of China in 1919 (Hui-Ping Liu and Wen 2007). The second movement was the nationwide mobilization of women in production and contribution to socialist construction by the Communist Party of China (CPC) under the leadership of Chairman Mao Zedong in the People's Republic of China in the 1950s. Mao argued that men and women are the same and extolled women as having the capability to 'hold up half the sky' and to learn, work, and dress as men do (Hershatter 2004). The third movement was Mao's campaign for criticising Confucian and feudal ideas in the politically driven Cultural Revolution (1966-1976), during which socialist China attempted to increase the representation of women at all levels of political leadership (Sheridan 1976).

Despite these movements, discrimination against women was (and still is) prevalent. To rectify this, in 1999 the CPC-led state enacted a law to protect women's rights and interests by codifying the principle of gender equality as 'a basic state policy to realize equality between men and women' in political, economic, social, cultural, and family life (National People's Congress 2005, Article 2). In response to this law, the State Council (2001) issued a ten-year (2001-2010) national plan for enhancing women's decision-making and leadership roles in state and social affairs.

Similar to the Anglo-American literature, some studies on Chinese leadership, including school leadership, have reported 'stereotypical differences' between male and female leaders (see Table 1). Li (1999) argued that because of their past feminine socialisation and gender stereotypes, Chinese women leaders have different psychological traits, modes of thinking, and leadership styles than their male counterparts. Li further argued that Chinese male leaders are confident in their ability and performance, are rational in decision-making, and attribute their leadership problems to external factors, while Chinese female leaders are less confident and attribute problems to their own lack of ability.

In one way or another, studies on Chinese school leadership have exhibited stereotypical differences between Chinese male and female school leaders that are similar to Lowe's (2003) dichotomies in leadership orientations between Chinese and Anglo-American traditions. Yafang Chen (2007) and Zhang (2010), for example, noted that male school leaders tend to stay competitive, and their female counterparts are inclined to focus more staff's individual and collective interests and concerns. Zhang (2010) contended that male school principals are more task-oriented and tend to adopt paternalistic styles emphasising distinctions between superordinates and subordinates and control over staff and resources, 
while female school principals tend to employ intuition for unfolding change and generating new ideas to improve their leadership, and adopt interpersonal styles by focusing on relationship-building and emotional aspects of teachers' and non-teaching staff's experiences. Female school principals, as Zhi and Zhang (2003) noted, have better social skills in the interpersonal domain of cultivating and managing relations with staff and fostering cohesion than their male counterparts. Unlike the Anglo-American literature, however, studies on Chinese school leadership seldom, if ever, report Chinese school leaders' patterns of 'no differences' and 'non-stereotypical differences'. As shown later, this study found that these two patterns coexisted with the stereotypical one among surveyed Chinese school leaders.

The Anglo-American literature of leadership and gender and specific studies on Chinese leadership and gender can shed light on patterns of similarities and differences between Chinese male and female school leaders in leadership preferences and practices. Neither literature, however, is specific enough to address two major, important questions about Chinese school leadership. First, in what ways and to what extent is gender related to Chinese school leaders' leadership preferences and practices, as well as the political influences on their choices? Second, why do Chinese female school leaders, as this project found and as is explained later, more strongly support orientations associated with masculine leadership than their male counterparts.

\section{The study}

\section{Background}

China has the largest school system in the world. In 2010, its student enrolment amounted to 253 million: about 29.8 million in 12,200 pre-schools and kindergartens, 99.4 million in 257,400 primary schools, 52.8 million in 54,900 junior-secondary schools, 46.8 million in 28,600 senior-secondary schools, 426,000 in 1,706 special schools, and 23.9 million in over 2,400 higher-education institutes (Ministry of Education 2011). In 1978, China began to implement the policy of reform and opening to the world. To enhance its national competitiveness, China attempted to raise the quality of its human resources by introducing nine-year compulsory schooling in 1986 and expanding higher education in the 1990s. In response to domestic social change and external challenges, including globalization, in the early 2000s, China reformed its school curriculum. China's schools, especially universities, have increased their exposure to and exchanges with Western countries, such as Britain and the United States.

Financially, most of China's schools (and universities) are confronting problems of low educational investment. Although China's state promised to increase the percentage of the gross domestic product (GDP) on public educational expenditure from 2.79 percent in 2004 to 4 percent by 2012 (Communist Party of China Central Committee and State Council 2010), this figure is still lower than the world average (e.g., 4.6 percent in 2009) (World Bank 2010). Moreover, since the 1980s, the unequal pace of economic development has exacerbated school-level disparities between and within geographic areas. Schools in the eastern (i.e., coastal) region of China, on average, have better conditions (in terms of finance, teachers' qualifications, and facilities) than their counterparts in the middle and western regions (Yuan 2005).

Regarding educational administration, China's state exercises tight control of the school curriculum and the appointment of school principals. As in state governance, education and politics are integrated. Students of all levels are required to take compulsory CPC-oriented political and ideological education (Vickers 2009). Principals are often CPC 
members and many schools have party organs and school party secretaries. Both principals and party secretaries are often called school leaders (see more later). According to its first national survey on principals conducted in 2008, China had 536,000 school principals, of which $87.3 \%$ were male and $12.7 \%$ were female (Xu 2009). (Public national statistics about school party secretaries are not available.)

\section{Research Methods}

This study is part of a project that explored how Chinese school leaders' adoption of leadership orientations reflects Lowe's (2003) dichotomies between Chinese and AngloAmerican leadership. This study focuses on gender and Chinese school leadership and addresses two specific research questions: (1) In what ways and to what extent are Chinese male and female school leaders similar and different in their leadership orientations? (2) Why do these patterns of similarities and differences exist?

Between February and June 2008, the project used an anonymous questionnaire survey and semi-structured interviews to collect data. These two methods complement each other in such a way that the former helped identify the views of a larger sample of Chinese school leaders, while the latter enabled in-depth probing with a smaller sub-sample of Chinese school leaders (Cohen et al. 2007; Wiersma and Jurs 2004). It should be noted that these two methods allowed respondent school leaders to self-report their perceptions, attitudes, and values, but they were not true observations of their leadership styles in practice. In China, it was (and is) difficult to gain access to Chinese school leaders for surveys and interviews, not to mention opportunities for observing their daily leadership styles.

The questionnaire was comprised of two parts. The first part collected respondents' personal and basic school information. The second part investigated the gender differences of Chinese school leaders on seven major leadership orientations (see Table 3). A majority of survey items of the first six orientations were adapted from Lowe's (2003) six theoretical constructs, which constituted three cultural dichotomies: cooperative-collectivist versus competitive-individualistic, autocratic/paternalist versus democratic, and intuitive versus rational. These constructs were adopted mainly because they, as demonstrated earlier, were already used to analyse Chinese leadership and could provide a useful reference for this study to compare Chinese leadership with leadership in other cultures. Moreover, these three cultural dilemmas, as examined earlier, are similar to gender stereotypes between male and female leaders in Anglo-American and Chinese traditions. The items of the autocratic/paternalist orientation were supplemented by those of Hong and Engeström (2004), which are more concrete and specific. A new domain, the interpersonal (or relation-building) orientation, was added to explore Chinese school leaders' preferences and practices in cultivating interpersonal relationships with staff, parents, and government officials, because many gender studies consider interpersonal styles as a stereotypical gender difference and because relationship (guanxi) has been a major form of transactional governance in Chinese paternalistic leadership (Howard Davies et al. 1995; 2003). A five-point Likert scale was used to allow school leaders to show the extent of their agreement, ranging from $1=$ strongly disagree to $5=$ strongly agree.

The survey was piloted with five Chinese principals to check the appropriateness, clarity, difficulty, and readability of question items and response options. After the pilot, the wording of some response options concerning school and personal information was slightly modified. In the final questionnaire, items were mixed to prevent respondents from stereotype answering (Forza 2009). It took respondents about 20 minutes to complete the questionnaire. The quantitative data were analysed with the Statistical Package for Social Sciences (SPSS). The project used $t$ tests to compare the means of male and female school leaders in order to 
identify items that were statistically significantly different between the two groups (Jackson 2011). As a result, means, rather than percentages, of response options were used so as to avoid unnecessary repetition in reporting.

\section{[Table 2 about here]}

The sample included Chinese school leaders from nine areas distributed in eastern, middle, and western regions of China. Through personal connections and making use of opportunities available in workshops for school leaders, a total of 360 questionnaires were distributed and collected. Of them, 347 (96.4\%) were useable. Of the respondents, 54.7\% were male and $45.3 \%$ were female; $37 \%$ were principals, $10.4 \%$ were school party secretaries, $35.5 \%$ were vice principals, $13 \%$ were both principals and party secretaries, $4 \%$ were principals and deputy party secretaries, and $1 \%$ were party secretaries and vice principals (Table 2). About $40 \%$ had been leaders for five years or less; $35 \%$, six to 10 years; and the rest, over 10 years. Regarding the geographical distribution in China, 69.2\% worked in the eastern region (which is more developed than other parts in China), $28.5 \%$ in the middle region, and $2.3 \%$ in the western region. With regards to level of development, about $75 \%$ of school leaders worked in urban areas and $25 \%$ in rural areas.

The project also included semi-structured interviews with school leaders to obtain indepth information. Four broad questions were used: (1) What are the major features of your leadership style? Why? (2) What were your major concerns in school leadership in the last 12 months? Why? (3) What are the major mechanisms through which your leadership can be realized? (4) How do you see your relationships with your staff, parents, and educational officials in charge of your school? Although it is difficult to access Chinese school leaders for interviews about themselves, 20 school leaders (who were also survey respondents and were accessed through personal connections) agreed to be interviewed. These included 18 principals and 2 deputy principals; 13 were males (see more information in Table 2). The interviews were conducted on an individual basis and took about 70 minutes each. To facilitate data analysis, interviews were audio-recorded with permission and transcribed into text.

\section{Major survey findings: coexistence of mixed gender-related leadership patterns}

This section presents the questionnaire survey's findings about gender and school leadership in China. The findings reveal the coexistence of mixed gender-related leadership patterns among surveyed Chinese school leaders, rather than the domination of one over others. The first finding indicates a broad pattern of leaders' self-reported preferences and practices, and within this broad pattern are three patterns showing no differences, stereotypical differences, non-stereotypical differences between male and female school leaders. (These survey findings will be elaborated and explained with interview data in the next section.) Some data on autocratic and interpersonal orientations have been reported in Law (2009; 2012).

\section{[Table 3 about here]}

The first and broad pattern reflects Chinese male and female respondents' strong support for leadership domains that are more associated with their own gender, and in some instances, the opposite one. Of the seven leadership domains, they gave high ratings to nearly all (30) items, with 23 items having means $(M)$ ranging from 4.08 to 4.84 (with 4 and 5 representing agreement and strong agreement, respectively), and their tendency to agree 
(rather than disagree) on 7 items, with means ranging between 3.24 and 3.97 (with 3 and 4 representing no preference and agreement, respectively) (Table 3). In particular, Chinese male and female school leaders, on the one hand, highly rated items on leadership domains that are more associated with their own gender. Chinese male school leaders indicated their strong emphasis on competitive-individualist, autocratic/paternalistic, and rational orientations, whereas their female counterparts indicated a strong stress on the cooperativecollectivist, democratic, intuitive, and interpersonal orientations. At the same time, however, Chinese male and female school leaders gave high ratings to items on domains that are more associated with opposite gender, such as male leaders' great stress on the cooperativecollectivist orientation and female leaders' strong support for the rational orientation (see more later). Although these high ratings do not mean that there are stereotypical or nonstereotypical differences, they revealed the strong tendency of Chinese male and female school leaders for cross-gender homogeneity, as discussed in the Anglo-American literature (e.g., Coleman 2003; Thompson 2000).

The second pattern of Chinese school leadership showed 'no differences' between Chinese male and female leaders in leadership preferences and practices on the autocratic/paternalist orientation, which is supposed to be more associated with masculine leadership. As shown on the third orientation in Table 3, all (four) items showed very slight differences in means $(M D)$ between Chinese male and female leaders by about .1, and none of these differences was statistically significant.

The third gender-related sub-pattern is related to "stereotypical differences" between responding Chinese male and female school leaders. Despite small differences, this is reflected in Chinese female school leaders' higher means than their male counterparts' with statistically significant differences in items on four leadership orientations that are more traditionally associated with female leadership. First, Chinese female school leaders gave higher ratings to the cooperative-collectivist orientation: promoting cooperation among teachers $(M D=.20, p<.001)$, settling disputes by negotiation $(M D=.14, p<.05)$, and not emphasising personal interest/rewards $(M D=.44, p<.01)$. Second, Chinese female school leaders placed greater stress on the democratic orientation than their male counterparts: promoting team spirit $(M D=.13, p<.01)$ and encouraging teachers to participate in school administration $(M D=.27, p<.01)$. Third, they attached greater importance to elements of the intuitive orientation: using past experience to find out what works best $(M D=.36, p<.01)$, maintaining harmony and consensus among teachers $(M D=.32, \mathrm{p}<.001)$, cultivating unfolding change $(M D=.22, p<.01)$, using ways/methods that work for the school $(M D$ $=.19, p<.01)$, and treating problems as wholes $(M D=.19, p<.01)$. Fourth, Chinese female leaders gave higher ratings to such items on the interpersonal orientation as consulting parents before introducing important school policy $(M D=.47, p<.001)$, cultivating and keeping good relationships with parents $(M D=.33, p<.001)$, and emphasising personal care and relationships in school administration $(M D=.15, p<.05)$.

Unlike the third pattern, the fourth gender-related pattern of Chinese school leadership reflects "non-stereotypical differences" of Chinese female school leaders. As compared with their male counterparts, they gave statistically significantly higher ratings to items of two leadership domains that are more associated with masculine leadership. For the competitiveindividualistic orientation, Chinese female school leaders gave higher ratings to promoting competition among staff for performance $(M D=.27, p<.001)$, teachers' efficiency $(M D$ $=.23, p<.001)$, and teachers' professionalism $(M D=.30, p<.001)$. In the rational orientation, they also gave stronger support to such leadership preferences and practices as dividing issues into measurable variables $(M D=.29, p<.01)$, objectively analysing 
information before acting $(M D=.24, p<.001)$, and winning arguments with facts/proof $(M D$ $=.25, p<.001)$.

\section{Discussion: possible explanations}

The questionnaire survey shows that mixed patterns of gender-related leadership preferences and practices coexisted among responding Chinese school leaders, including stereotypical differences in orientations that are more associated with female leadership, no differences in the autocratic/paternalist orientation, and non-stereotypical differences of female school leaders in domains that are more associated with masculine leadership. This section suggests some possible explanations, which are grounded in interview data, for such coexistence. These patterns, as this section argues, result from the interplay between traditional Chinese culture and contemporary Chinese politics. Moreover, Chinese school leaders in general and female leaders in particular needed to employ leadership styles from the opposite gender to supplement their own, with a view to meeting leadership expectations that required traits and styles of both genders.

\section{Continuing influences of traditional Chinese culture}

Surveyed Chinese male and female school leaders gave similarly high ratings to leadership orientations that were more associated with their own gender (i.e., the first and broad genderrelated pattern), and, in particular, indicated "stereotypical differences" in their adoption of leadership styles and practices on orientations that were more associated with feminine leadership: cooperative-collectivist, democratic, intuitive, and interpersonal (i.e., the second pattern). Such gender differences, as some management studies (such as Grant 1988; MacLeod 1994) have explained, could be a result of experiences in earlier cultural socialisation reinforcing masculinity in males and femininity in females, and/or different stereotypical expectations they may be called upon to meet. In the case of China, surveyed Chinese school leaders were still living in and were socialised into a context where Chinese cultural assumptions and stereotypical perceptions about the nature and social roles of males and females have not been eradicated.

Although the CPC-led state has made some improvements on raising women's status and participation in society, economy, and politics since the 1950s, cultural stereotyping of males and females in China is still prevalent. The State Council (2011) admitted that social discrimination against women has not been eradicated and that the level of women's participation in decision-making and management is 'still relatively low'. Chinese leadership continues to be predominantly occupied by males, and women are still underrepresented in various sectors, including the state and education (National People's Congress Standing Committee 2010; Zhang 2010). Cultural stereotypes regarding social roles between males outside home and females at home is also common in China's urban areas, such as Shanghai (not to mention rural areas) (Hui-Ping Liu and Wen 2007).

As in the questionnaire survey, interviewed Chinese school leaders expressed a similar cultural legacy of gender stereotyping. Many interviewed male and female school principals attributed their employment of leadership styles and practices that were more associated with their own gender to cultural socialisation and gender-related expectations within and outside family. A male principal (P14), for example, recalled his parents' instruction about the importance of men being 'strong, independent, and decisive'. His father reminded him to be a man by 'staying competitive' and 'not shedding tears', even in times of hardship. A female principal (P8) acknowledged that she had been taught to be submissive to 
elders in her family, including grandparents. She also recalled that she needed to help her mother in housework and learned social and communication skills from her mother to help maintain harmony in the family.

Many female school leaders must change their role from leaders in school to caretakers at home. All interviewed female school leaders admitted that they had to bear 'dual responsibilities' (shuangchong zhize): managing and taking care of their staff during school time and looking after their husbands and children and doing housework after school and during holidays. Unlike their female counterparts, many interviewed male school leaders did not need to change their role and could continue as leaders of their families. In interviews, some male school leaders (such as P4 and P10) expressed that they did share some housework, but they could spend most of their time 'concentrating' (zhuanzhu) on school affairs because their wives helped them take care of all family matters.

\section{Reinforcement of Chinese paternalistic culture by contemporary political culture}

On the autocratic/paternalist orientation in the questionnaire survey, both responding Chinese male and female school leaders showed "no differences" with statistical significance (i.e., the third gender-related pattern). They indicated their tendency to emphasise observing rules, order, and obedience in leading and managing their staff. Similar to the perpetuation of gender stereotypes, this could be partly explained by the continuing influences of traditional Chinese culture on school leadership, regardless of gender. This is supported by the analysis of interview findings. This analysis suggests that one major purpose of emphasising social rules and obedience is to keep harmony in schools. An interviewed male principal (P1) serving in Xinjiang in western China admitted that he adopted Confucian thoughts, particularly the 'doctrine of mean' (a principle advocating not going to extremes but taking a balanced approach) in leadership by, on the one hand, stressing performance regardless of seniority, and on the other hand, emphasising obedience, order, and 'seniority by ranking and years of experience' (lunzi paibei) so as to keep order and harmony between experienced and young teachers. Like this male principal, an experienced female principal (P3) from Shanxi in central China with 19 years of leadership experience expressed that she kept 'peace and harmony' (pinghe) among staff by establishing order and fostering respect for the school's authority and therefore hers.

Unlike gender stereotypes in the traditional Chinese culture which the CPC-led state has attempted to eradicate, the paternalistic feature of Chinese leadership in education has been reinforced by the CPC's policy of integrating education and politics and, in particular, putting school leadership under the CPC's leadership. Since the CPC's assumption of power in 1949, education in socialist China has been stipulated as an important means to construct socialist modernization and train constructors and successors for the socialist cause (National People's Congress 1995, Article 5). To ensure the fulfilment of this task, the CPC-led state institutionalized the principal-responsibility system under the CPC's leadership (Communist Party of China Central Committee 1985). The principal is responsible for school administration, whereas the school party secretary is responsible for political and ideological work on campus. Both posts are of the same rank; the education department and the party organisation of concerned local authorities, respectively, control their appointments. They exercise power through a vertical, three-tiered structure, ranging from the school leadership stratum to subject or grade heads and then to teachers (Law 2012). Moreover, the power distribution between principal and school party secretary is intertwined. Many school principals (such as P1, P4, and P10 in this study) take up the post of the deputy school party secretary, whereas school party secretaries (e.g., P11) are deputy school principals. Sometimes the school principal (like P15) is concurrently the school party secretary. In an 
interview, a male principal who was also a deputy school party secretary (P4) explained that such intertwining in leadership posts could facilitate their communication and allow school administration and party work to be 'interpenetrated'.

Analysis of interview findings further reveals that regardless of gender, school leaders enforce the CPC-led state's will and policy in education. In separate interviews, two female principals (P2 and P3) explicitly expressed that a major task of school leadership was 'to consistently implement the party's (CPC's) policy'. Similarly, an interviewed male principal (P17) indicated that such implementation across all levels in school is 'fundamental', and another male principal (P14) serving in Shanghai even remarked: 'We absolutely listen to the party's command'. In explaining their faithfulness to the CPC, one oft-cited reason was their close relationship with the ruling party in one way or another; for example, they were 'cultivated' (P6), 'trained' (P11), and 'sent' to school (P2) by the CPC.

\section{Strong pressure on female school leaders for cross-gender adjustment to meet institutional expectations and needs}

In addition to adopting the autocratic/paternalist orientation like their male counterparts, in the questionnaire survey, responding Chinese female leaders indicated, as the fourth genderrelated pattern, some strong non-stereotypical differences in leadership preference. Surveyed Chinese female school leaders gave stronger support to items in the competitiveindividualistic and rational orientations, which are more associated with male leadership, than their male school leaders, with statistically significant differences. This suggests that they made up for deficits from early socialisation by selectively developing or adopting masculine leadership's traits and styles. This could be partly because as in other societies such as the United States (Cubillo and Brown 2003; Powell 1997), female school leaders in China face practical demands for meeting their organisations' needs and expectations for good leadership, which require both masculine and feminine leadership traits and styles.

As compared with their male counterparts, however, Chinese female school leaders, as further revealed in interviews, faced an additional challenge, as they have a stronger need to use both male and female traits and styles to fight stereotypical discrimination, especially early in their leadership careers. This discrimination was well-captured in the struggle of the youngest interviewed female school principal (P2), who was in her mid-30s and had only three years of leadership experience. She expressed that despite her unwillingness, she had to be or at least appear to be 'strong and tough' in front of her subordinates, because many of them had been used to being led by male principals and often compared her leadership style and performance with her male predecessors'. She further explained that some colleagues, including female ones, 'did not like to be headed by a woman' and doubted the ability of women leaders. Similar gender discrimination still happened to an experienced female principal (P15) who was also her school's party secretary and had over 10 years of leadership experience. She remarked that although her male deputy principals would 'not openly challenge her but pretend to be convinced' (koufu xin bufu), she needed to maintain a strong leadership image.

To tackle this discrimination and help female school leaders become as competitive as their male counterparts, in the mid-2000s some China leadership studies (e.g., Yafang Chen 2007) began to encourage them to adopt masculine leadership by, for example, being objective and using scientific methods in decision-making and handling daily school affairs. Surveyed Chinese female school leaders in this study revealed a change in their perception of Chinese school leadership from mainly a traditional masculine-feminine leadership paradigm to their high acceptance of adopting non-stereotypical leadership styles on the rational and competitive domains. 
Moreover, all interviewed female school leaders insisted that they did not need to deliberately change their so-called female traits and characteristics, and most argued that similar to male school leaders, they were appointed because of their capability and performance, rather than gender. Most interviewed female principals (such as P2, P3, and P8), however, used a two-pronged approach to build their leadership image and win subordinates' trust and confidence in their leadership. On the one hand, they, as examined earlier, made use of their own female traits, such as caring, to improve communication and build good relationships with teachers, parents, and local officials.

On the other hand, in one way or another, most interviewed Chinese female principals suppressed some female traits that might be deemed inconsistent with male leadership and tried their best act in accordance with expectations for male principals. They tried to appear as rational, rather than emotional, school leaders. For example, a female principal (P3), with 18 years of leadership experience, remarked that on important issues or new initiatives, such as internal curriculum reform in the mid-2000s, she often reminded herself to not give her 'teachers a feminine impression that she was subjective and emotional' and would employ a rational orientation, for example, by presenting to her staff the reasons for the seriousness of problems confronting the school and pros and cons of her new initiatives.

Moreover, while promoting teachers' cooperation and collective interests, all interviewed female principals, similar to their male counterparts, emphasised competition among teachers in the competitive-individualistic orientation for three major reasons. First, in the China's school education sector, competition is a widely adopted mechanism for teachers, regardless of their gender, to demonstrate performance, gain peer and public recognition, and receive promotions (Law 2009). Major areas of teachers' competition include: demonstration of teaching quality through public lessons (in which teachers open their class to other teachers of the same school and/or other schools for observation), publication of their research on teaching in local and national journals, and students' examination scores and rates of promotion to good schools at the next level. Second, such competition is related to the survival and competitiveness of individual schools. Some female principals (e.g., P8 and P15) warned that if they did not foster a culture of competition but others did, their teachers 'would not make progress' and their schools 'might lag behind' other schools in, for example, public recognition and student intake. Third, encouraging competition for performance and promotion could help female principals fend off gender-related challenges to or doubts about the ability of women leaders. In an interview, a female principal (P16) explained that competition could provide her colleagues with a 'more open and more transparent mechanism' to obtain 'more objective' evidence that she could use in staff appraisals and promotions, and that this had helped her 'avoid unnecessary rumours or complaints' about gender-related favouritism and discrimination.

\section{Conclusion}

In response to Oplatka's (2006) call for studies from developing countries to supplement the Anglo-American dominated literature, this article has examined the relationships among culture, gender, and school leadership in China. This study has demonstrated that mixed patterns of gender differences in Chinese school leadership coexist in such a way that there are no conspicuous gender differences in the adoption of an autocratic/paternalist orientation, but statistically significant 'stereotypical differences' on four orientations that are more associated with feminine leadership and statistically significant 'non-stereotypical differences' of Chinese female leaders on the other two orientations, which are more associated with masculine leadership. This finding is broadly consistent with Eagly and Johnson (1990), which found both the presence and absence of gender differences in Anglo- 
American leadership. Unlike Eagly and Johnson (1990) and Powell (1997), however, this study did not find that responding Chinese male school leaders' had a stronger tendency to employ autocratic leadership than their female counterparts, but found statistically significant, 'stereotypical differences' between the two sexes in the interpersonal orientation.

Moreover, unlike other extant Chinese school-leadership studies (e.g., Zhi and Zhang 2003), this study has shown that responding Chinese female school leaders have a greater tendency for cross-gender adjustment than their male counterparts, as reflected in their marked 'non-stereotypical differences' with statistical significance. In particular, they needed leadership traits and styles in competitive-individualist and rational domains (which are more associated with masculine leadership) to fight stereotypical discrimination against women's leadership and to meet social and institutional expectations and needs for good leadership in the male-dominated Chinese culture. The coexistence of mixed gender-related patterns of Chinese school leadership, as this paper has explained from both cultural and social perspectives, has been a complex interplay among surveyed Chinese school leaders, gender factors, and extra-gender factors, including traditional Chinese culture, the contemporary China's political environment, and the school settings in which their school leadership was shaped and exercised.

China's case has three major, related theoretical implications for understanding culture, gender, and school leadership. First, conspicuous stereotypical and non-stereotypical differences of either Chinese male or female school leaders reflect that they can amalgamate leadership traits and styles of both genders according to institutional needs and conditions. This suggests that while school leaders' leadership traits and styles continue to be influenced by their early socialisation, they can choose to re-socialise into values and norms as expected by their schools.

The second theoretical implication is concerned with the role of culture as an extragender force in shaping male and female school leaders' leadership preferences and practices. In male-dominated societies, culture can play two contrasting roles in shaping the relationship between gender and leadership. On the one hand, as a force of divergence, culture can maintain and perpetuate traditionally perceived gender differences between men and women. On the other hand, as a convergent force, culture can have stronger influences on certain leadership preferences and practices than gender-stereotypical ones. As this study has shown, the Chinese paternalistic culture in CPC-led China is reinforced by integrating politics and education and through a vertical power hierarchy in the state structure and schools. The evidence showing no statistically significant differences between surveyed Chinese male and female school leaders in the autocratic/paternalist leadership orientation suggests that to a similar extent, such reinforcement shapes the preferences and practices of the two sexes in this leadership orientation.

The third theoretical implication is related to the universality of gender differences in school leadership across cultures. In male-dominant cultures, including Anglo-American and Chinese societies, it is difficult to eradicate stereotypical perceptions of gender differences. China's case shows that despite the efforts of nationwide ideological and political movements to replace Chinese traditional culture between the 1950s and late 1970s and legal means to enforce gender equality since the 1980s, two traditional gender stereotypes - males' superiority over females and separation of men's and women's social roles - still prevail in contemporary Chinese culture.

At the same time, however, perceived gender differences in school leadership can vary in expression and extent across cultures and over time within cultures. The patterns of gender differences in school leadership in China, as this study has shown, are different from those in Anglo-American societies. Such differences probably reflect the cultures' different 
values, norms, and expectations regarding gender roles, and leadership, which in turn can differently refract into and be reflected from school leaders' leadership preferences, behaviours, and practices. Moreover, as culture is not static, neither is school leadership. In China, the increasing acceptance and adoption of cross-gender leadership traits and behaviours by male and female school leaders represents the beginning of a significant, though very gradual, shift away from a traditional masculine-feminine paradigm. As in Anglo-American societies, however, women leaders in China are confronted with more gender-related challenges during this shift than men leaders. The battle of women leaders to fight a longstanding and deep-seated cultural preference for male leadership and discrimination against female leadership is not over yet, and more concerted efforts of major stakeholders (including government, school leaders, teachers, and the public) are needed to break the 'glass ceiling' for women.

In sum, this exploratory study shows that China's school leadership is affected by gender- and extra-gender factors, including the cultural, political, and school contexts in which leadership is shaped and exercised. It should be noted that this study has limitations, including the self-reporting nature of its fieldwork data and its small scale and nonrepresentativeness of responding Chinese school leaders, relative to the vastness and diversity of China. Its findings should be further tested with more research in China. More international and comparative studies are required to identify how different chemistries of culture, state-school relationships, and schools in different societies affect the relationship between gender and school leadership.

\section{References}

Ceng, S. 2005. Zhongguo shi guanli [Chinese style of management]. Beijing: China Social Sciences Press.

Chen, F. 1998. Xingbie: Yige duoyuanxing de fanchou [gender: A multiple discipline]. Funu Yanjiu Luncong [Collection of Women's Studies] 4: 8-12.

Chen, Y. 2007. Lun chenggong nu xiaozhang de suzhi tezheng [on the quality characteristics of successful female principals]. Jiaoyu Yanjiu [Educational Research] 2: 89-91.

Cohen, L., L. Manion and K. Morrison. 2007. Research methods in education. 6th ed. London: RoutledgeFalmer.

Coleman, M. 2003. Gender \& leadership style: The self-perceptions of secondary headteachers. Management in Education 17, no. 1: 29-33.

Communist Party of China Central Committee. 1985. Reform of China's educational structure. Beijing: Foreign Languages Press.

Communist Party of China Central Committee and State Council. 2010. Guojia zhong changqi jiaoyu gaige he fazhan guihua gangyao (2010-2020 nian) [outline of China's national plan for medium and long-term education reform and development (20102020)]. Zhongguo Jiaoyubao [China Education Daily], 30 July.

Cubillo, L. and M. Brown. 2003. Women into educational leadership and management: International differences? Journal of Educational Administration 41, no. 3: 278-91.

Davies, H., T.K.P. Leung, S.T.K. Luk and Y.H. Wong. 1995. The benefits of guanxi: The value of relationships in developing Chinese market. Industrial Marketing Management 24, no. 3: 207-14. 
Davies, H., T.K.P. Leung, S.T.K. Luk and Y.H. Wong. 2003. Guanxi and business practices in the People's Republic of China. In Chinese culture, organizational behavior, and international business management, ed. I. Alon, 27-40. Westport, Conn.: Praeger.

Davies, L. 1987. Research dilemmas concerning gender and the management of education in third world countries. Comparative Education 23, no. 1: 85-94.

Dimmock, C. and A. Walker. 2000. Introduction - justifying a cross-cultural comparative approach to school leadership and management. School Leadership and Management 20, no. 2: 137-41.

Donnell, S.M. and J. Hall. 1990. Men and women as managers: A significant case of no significant differences. Organizational Dynamics 8: 60-76.

Dorfman, P.W., P.J. Hanges and F.C. Brodbeck. 2004. Leadership and cultural variation: The identification of culturally endorsed leadership profiles. In Culture, leadership, and organizations: The globe study of 62 societies, eds. R.J. House, P.J. Hanges, M. Javidan, P.W. Dorfman and V. Gupta, 669-719. Thousand Oaks, Calif.: Sage.

Eagly, A.H. and B.T. Johnson. 1990. Gender and leadership style: A meta-analysis. Psychological Bulletin 108, no. 2: 233-56.

Eagly, A.H., S.J. Karau and B.T. Johnson. 1992a. Gender and leadership style among school principals: A meta-analysis. Educational Administration Quarterly 28, no. 1: 76-102.

Eagly, A.H., M.G. Makhijani and B.G. Klonsky. 1992b. Gender and the evaluation of leaders: A meta-analysis. Psychological Bulletin 111, no. 1: 3-22.

Ferrario, M. 1994. Women as managerial leaders. In Women in management: Current research issues, eds. M.J. Davidson and R. Burke, 110-28. London: Paul Chapman.

Fidler, B. 2000. Editorial: The need for a situational and contextual framework for school improvement. School Leadership and Management 20, no. 2: 133-36.

Forza, C. 2009. Surveys. In Researching operations management, ed. C. Karlsson. New York, NY: Routledge.

Grant, J. 1988. Women as managers: What they can offer to organizations. Organizational Dynamics 16, no. 3: 56-63.

Gray, H. 1987. Gender considerations in school management: Masculine and feminine leadership styles. School Leadership \& Management 7, no. 3: 297 - 302.

Hershatter, G. 2004. State of the field: Women in China's long twentieth century. The Journal of Asian Studies 63, no. 4: 991-1065.

Hofstede, G. 1980. Culture's consequences: International differences in work-related values. Beverly Hills, CA: Sage.

Hofstede, G. 1984. Cultural dimensions in management and planning. Asia Pacific Journal of Management 1, no. 2: 81-99.

Hofstede, G. 2007. Asian management in the 21st century. Asia Pacific Journal of Management 24, no. 4: 411-20.

Hong, J.Z. and Y. Engeström. 2004. Changing principles of communication between Chinese managers and workers: Confucian authority chains and guanxi as social networking. Management Communication Quarterly 17, no. 4: 552-85.

Jackson, S.L. 2011. Research methods: A modular approach. 2nd ed. Belmont, CA: Wadsworth.

Krüger, M.L. 2008. School leadership, sex and gender: Welcome to difference. International Journal of Leadership in Education 11, no. 2: 155-68.

Law, W.-W. 2009. Culture and school leadership in China: Exploring school leaders' views of relationship- and rule-based governance. In Educational leadership: Global contexts and international comparisons, ed. A. Wiseman, 303-41. Bingley: Emerald Publishing. 
Law, W.-W. 2012. Educational leadership and culture in China: Dichotomies between Chinese and Anglo-American leadership traditions? International Journal of Educational Development 32, no. 2: 273-82.

Li, H.Y. 1999. Nuxing lingdao de shuangchong shenfen yu shuangchong zeren [female leaders: Double identities and double responsibilities]. Zhongguo Fuyun [Chinese Women's Movement] 9: 29-30.

Liu, H.-P. and Z.-F. Wen. 2007. Rujia nuxingguan zhi yanbian ji fansi [on historic changes of Confucianist outlook on women and its modern reflection]. Huazhong Nongye Daxue Xuebao (Shehui Kexue Ban) [Journal of Huazhong Agricultural University (Social Science Edition)] 3: 78-81.

Liu, P. 1997. Adjusting to a new society: A study of educated Chinese women's acculturation in the United States. Advancing Women in Leadership 1 (no. 1), http://advancingwomen.com/awl/awl_wordpress/ (accessed 14 April 2011).

Lowe, S. 2003. Chinese culture and management theory. In Chinese culture, organizational behavior, and international business management, ed. I. Alon, 1-2. Westport, Conn.: Praeger.

Macleod, J.S. 1994. Women in management: What it will take to attain truly equal opportunity. In Our vision and values: Women shaping the 21st century, ed. F.C. Hutner, 40-46. Westport, CT: Praeger Publishers.

Ministry of Education. 2011. 2010 nian guanguo jiaoyu shiye fazhan tongji gongbao [statistical report on educational achievements and developments in China in 2010]. Zhongguo Jiaoyubao [China Education Daily], 6 July.

National People's Congress. 1995. Zhonghua renmin gongheguo jiaoyufa [the education law of the People's Republic of China]. In Zhonghua renmin gongheguo jiaoyufa, yiwu jiaoyufa, jiaoshifa [the education law, basic education law and teachers law of the People's Republic of China], 1-13. Beijing: China Law Publishing House.

National People's Congress. 2005. Zhonghua renmin gongheguo funu quanyi baozhang fa (2005 xiuzheng) [the law of the People's Republic of China on the protection of women's rights and interests (amended in 2005)]. Beijing: National People's Congress.

National People's Congress Standing Committee. 2010. Guanyu jiancha zhonghua renmin gongheguo funu quanyi baozhang fa shishi qingkuang de baogao [report on the implementation of the law of the People's Republic of China on the protection of women's rights and interests]. Beijing: National People's Congress.

Oplatka, I. 2006. Women in educational administration within developing countries: Towards a new international research agenda. Journal of Educational Administration 44, no. 6 : 604-24.

Ozga, J. 1993. Introduction: In a different mode. In Women in educational management, ed. J. Ozga, 1-15. Buckingham: Open University Press.

Pace, A. and J. Pace. 2005. Gender differences in headership leadership and management styles: A study of a number of headteachers in maltest secondary schools. Journal of Maltese Education Research 3, no. 1: 61-79.

Powell, G.N. 1997. Leadership and gender: Vive la difference? In Women, men and gender: Ongoing debates, ed. M.R. Walsh, 298-306. New Haven: Yale University Press.

Powell, G.N. and L.M. Graves. 2003. Women and men in management. 3rd ed. Thousand Oaks, CA: Sage.

Qi, S.H., S. Wu and F. He. 2007. Wenhua jingzheng de shidai [the age of cultural competition]. In Daoben guanli: Zhongguo qiye wenhua gangling [dao-oriented management: The creed of Chinese corporate culture], ed. S.H. Qi, 1-16. Beijing: China Economy Publishing House. 
Sanchez, J.E. and B. Thornton. 2010. Gender issues in k-12 educational leadership. Advancing Women in Leadership 30 (no. 13), http://advancingwomen.com/awl/awl_wordpress/ (accessed 14 April 2011).

Sanders, K., T. Willemsen and C. Millar. 2009. Views from above the glass ceiling: Does the academic environment influence women professors' careers and experiences? Sex Roles 60, no. 5: 301-12.

Sheridan, M. 1976. Young women leaders in China. Signs 2, no. 1: 59-88.

State Council. 2001. Zhongguo funü fazhan gangyao (2001-2010 nian) [plan for the development of women in China, 2001-2010]. Beijing: State Council.

State Council. 2011. Zhongguo funü fazhan gangyao (2011-2020 nian) [plan for the development of women in China, 2011-2020]. Beijing: State Council.

$\mathrm{Su}, \mathrm{D}$. 2005. Dongfang guanli xue [theories of management in the east]. Shanghai: Fudan University Press.

Thompson, M.D. 2000. Gender, leadership orientation, and effectiveness: Testing the theoretical models of Bolman \& Deal and Quinn. Sex Roles 42, no. 11-12: 969-92.

Vickers, E. 2009. Selling 'socialism with Chinese characteristics' 'thought and politics' and the legitimisation of China's developmental strategy. International Journal of Educational Development 29, no. 5: 523-31.

Wiersma, W. and S.G. Jurs. 2004. Research methods in education: An introduction. 8th ed. Needham Heights, MA: Allyn \& Bacon.

World Bank. 2010. World development indicators 2010. Washington, DC: World Bank.

$\mathrm{Xu}, \mathrm{X} .2009$. Woguo shouci pucha zhongxiaoxue xiaochang renshu jin jiucheng xiaozhang shi nanxing [China's first national survey on principals of primary and secondary schools: Nearly $90 \%$ principals are male].

Yuan, Z.G. 2005. Yanjiu zhu baogao [a general report on the issue]. In Suoxiao chaju: Zhongguo jiaoyu zhengce de zhongda mingti [narrowing the gap: A key issue in China's educational policies], ed. Project Team of a Case Study on Key Educational Policy in Transitional China, 1-84. Beijing: People's Education Press.

Zhang, X. 2010. Nuren jiaoshu nanren guanxiao xianxiang tanxi [an analysis of the phenomenon of "women teaching and men management in school"]. Jiaoyu Fazhan Yanjiu [Research in Educational Development] 8: 30-36.

Zhi, T.J. and L.F. Zhang. 2003. Nandang de nu xiaozhang [it is not easy to be a female principal]. Jiaoyu Wenhui [Perspectives on Education] 11: 14-15. 